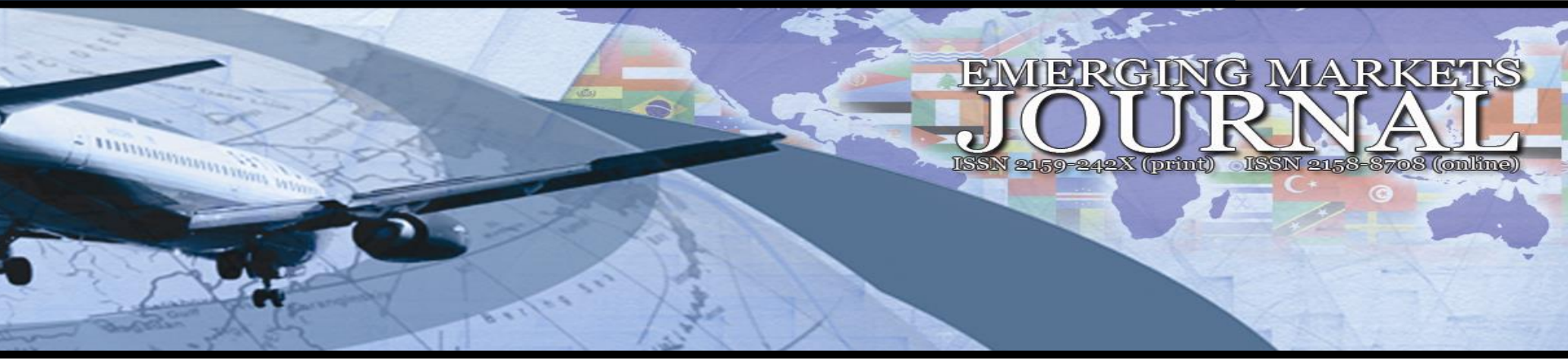

\title{
Hosting Major International Sports Events in a Country: A Socioeconomic Impact
}

\section{Girish Karunakaran Nair}

Stenden University of Applied Sciences, Qatar | e-mail: gknair75@gmail.com

\author{
Volume 11 No 1 (2021) ｜ ISSN 2158-8708 (online) ｜ DOI 10.5195/emaj.2021.207 | http://emaj.pitt.edu
}

\begin{abstract}
This research focuses on the impact of sponsoring major sports events concerned with the socioeconomic aspects of Qatar. Context is the hosting of FIFA 2022 in Qatar. A questionnaire has been developed based on the underpinning theory, which included seven dimensions of measuring socioeconomic impact that covered Micro, Meso, Macroeconomic, Employment, Quality of Life, Social Cohesion and Environmental aspects. Questionnaire survey was conducted for a sample size of 126, which included the managers from tourism industry and sponsoring of sports events. The research methodology involved descriptive statistics calculations using MS Excel and SPSS. The response score was collected on a 5-point Likert scale for quantitative measures and the Mean, Standard Deviation, Kurtosis, Skewness and Frequency Distributions were computed for seven dimensions. The responses were later categorized into degrees of agreement with a priori scale to understand the relative impact of sponsoring sports events concerned with socioeconomic aspects. The results have indicated that, the highest impact would be on the creation of Environmental Consciousness among the citizens of Qatar followed by the impact on the Micro, Meso and Macroeconomic aspects of the country. These revelations have led providing suggestions to policy makers, which would be useful particularly in the present situation where Qatar is planning for FIFA 2022.
\end{abstract}

Keywords: Sports Event, Tourism, Socio-Economic Impact, FIFA 2022, Qatar

\section{$(\mathrm{cc}) \mathrm{EY}$}

New articles in this journal are licensed under a Creative Commons Attribution 3.0 United States License.

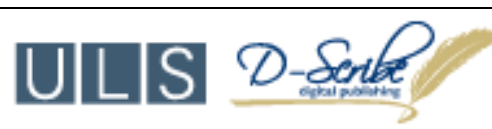

This journal is published by the University Library System of the University of Pittsburgh as part

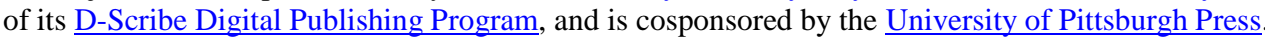




\section{Hosting Major International Sports Events in a Country: A Socioeconomic Impact}

\author{
Girish Karunakaran Nair
}

\section{Introduction}

Hosting the FIFA World Cup 2022 is going to be a mega event to be listed in the history of Qatar as it is going to be the center of attraction in the World. With a population of just 2 million people, Qatar is going to be the first Arab state to bring the world cup to the Arab world. It is not just a credit to Qatar, but to the entire Arab League as it is through the collaboration of the member states. So, while the event brings collaboration between the Arab world and the West, it also builds a higher level of teamwork between the Arab states. The event is not just a sport, but has an advanced technology to back-up the event. The modern solar technology will be used to maintain a temperature of $20^{\circ} \mathrm{C}\left(28^{\circ} \mathrm{F}\right)$ in the twelve stadiums in seven host cities, which are the venues for sport activities. This event would develop healthy international relations between the neighboring countries. One of the major considerations in bidding to host this event is the potential for the game to generate a wide range of benefits for the population of Qatar. The obvious benefits will be anticipated in addition to gaining international importance and developing local pride. The event would also provide improvements in employment, develop the economy of the country, improve housing facilities, provide better environment for business and promote sports at a much higher level. All these benefits can ultimately lead the socioeconomic development of the country. Thus, it is obvious that there is a need to conduct a systematic research on the study of the socioeconomic impact of sponsoring sports at the national and international level.

The aim of this research is to investigate the impact of sponsoring a major sports event, considering the socioeconomic aspects of Qatar. To accomplish this aim, the following objectives were developed: Identifying the dimensions of socioeconomic impact in the context of sponsoring a sports event with a specific reference to Qatar, determining the impact of sponsoring a sports event on the dimensions of socioeconomic aspects and making suggestions to the managers and the policy makers to draw upon the dimensions, which favorably impact the socioeconomic aspects of the country.

\section{Literature Review}

There are a number of studies which have attempted to build theories on how the hosting of games might influence the socioeconomic impact of the country (McCartney, 2010). There are another set of studies which have considered the likelihood of benefits which may arise through sponsoring major sports events, and the relative cost has also been examined (Brown \& Massey, 2001). Also, a number of studies has considered the impact of sponsoring sports events on host populations (Home, 2007). The Strengths, Weaknesses, Opportunities and Threats (SWOT) Analysis of hosting a sports event indicated that, the opportunities included evolution of the tourism industry, business expansions, rise in the quality of life, the usage of legacies post-event as well as the enhancement and improvement of infrastructures. Major threats were the financial burden of the event, increased pollution, dependence on the event to revive the economy, and the dislocation of residents (Karadakis, et al., 2010). While there are not many studies undertaken in the context of Qatar with reference to the specific issues, very little has been done particularly to study the socioeconomic impact of hosting the major sports events and a systematic approach to arrive at a suggestion which would allow the decision maker to make an improved judgement on the basis of the known effects and on areas of uncertainty. Thus, the major focus of this research is to concentrate on these issues. This study specifically focuses on the seven socioeconomic dimensions, which are micro, meso, macro-economic, employment, quality of life, social cohesion and security aspects as well as the environmental aspects (Georghiou et al., 2002).

Micro-economic aspects include firm-based capacities and efficiencies in connection to product and process improvements (Stoneman, 1995; Klette et al., 2000; Stabler \& Sinclair, 2010). Microeconomic aspects mainly focus on the action of individual buyers and sellers responding to the signals sent by price to set production and distribution of effort (Dopfer et al., 2004). This research is run to study the impact in the context of sponsoring a major sports event. The microeconomic aspects may include the capital market based on venture capitalists, the high level of information and communication infrastructure, qualified professionals, technology to support the design, good transportation infrastructure, ability in training graduates, good administration, developed human capital, diversified economy, good collaboration between clusters, government investments in advanced technology products and services as well as very demanding regulatory standards (Georghiou et al., 2002).

Meso-economic aspects refer to the aspects which are within the networks of innovation and it is a bridge between the two extreme paradigms of economics. Mesoeconomics basically look for the structure which is not reflected in the supply demand curves, Gross Domestic Product (GDP), inflation and unemployment rate (Mamalakis, 1996). Meso-econometric studies have recently been carried out in order to relate 'innovation' to 'firm's performance'. A positive association has been indicated between these two variables. Today's world of business is mainly centered on innovation activity undertaken by a firm. Tourism is an activity which can immensely benefit through innovation (Cefis, 2001). Sponsoring a sport event such as FIFA 2022 would mainly contribute to the tourism industry on mesoeconomic terms. The meso-economic measures include political economy, institutional economics, information theory and distribution of incentives among the sectors of the economy.

Macro-economic aspects is the study of entire economy in terms of total amount of goods and services produced, total income earned, the level of employment of productive resources, and the general behaviour of 
prices. Macroeconomics can be used to analyze how best to influence policy goals such as economic growth, price stability, full employment and the attainment of a sustainable balance of payments. This includes market and economy level increases in capacity and efficiencies, and the improvements to the stock of knowledge. The macroeconomic aspects consider wider issues such as employee compensation, proprietor's income, rental income, corporate profits, net interest, labour share, and capital share (Andolfatto, 2005).

Employment (EMP) is a very important component of socioeconomic aspect. Any progressive country should provide ample job opportunities for the job seekers. Sponsoring a sport event could lead to create more employment to hotels, catering and tourism (WTO, 2010). These three sectors are highly labour intensive. Employment through these three sectors could be both directly through jobs in the sector, and indirectly through supportive sourcing industries such as construction, agriculture, fishing, food processing, furniture, handicrafts, transport, utilities, arts and other services. Hosting of sports events demands skill assessments to identify the present and future needs, investment in education, vocational training, training upgrades and human resource development. These activities are vital for the operational efficiency enhancement to maintain international standards during the hosting of event to meet the expectations of international tourists visiting during the event. This would lead to the creation of employment opportunities.

Based on Quality of Life (QOL), Andereck et al. (2007) state that in general the impact studies are quantitative analyses based on the agreement or disagreement of the respondents. But when it comes to QOL, it should aim to understand how these impacts are internalised and influence individual's overall life satisfaction. Researchers have identified several dimensions of QOL which include standard of living, health, safety, community connectedness, achievement, relationships and spirituality (Uysal,et al., 2012). The existing literature also indicates that, there can be substantial impacts on the quality of life of residents after the event.

The observation was that, before the event the influence of political impacts, psychological impacts and social benefits on perceived QOL was significant and after the event, the economic impacts were significant (Kaplanidou, et al., 2013). Sports events generate interaction between the local culture and the global culture. This interaction will lead to an understanding ability of the locals to be more open to foreign cultures in order to build business relationship (Meethan, 2001). In this process, culture becomes more quantifiable so that clear estimation can be obtained for the similarity and differences between the local culture and the global culture (Smith, 2001). Ma \& Kaplanidou (2017) found that, the support provided to event is strongly influenced by quality of life of residents. Therefore, to improve event, support to legacies that improve QOL should be improved. The events and experiences during the sports events make the people develop an everlasting experience in their minds (Carr, 2002). A sort of homogenization between the local and global culture will take place. All these changes make the local citizens redefine their quality of life. Thus, there will be an impact produced by sponsoring a sports event in the country.
One of the areas which may be influenced by a sports event is Social Cohesion and Security (SOC). The event as such makes the citizens develop a sense of pride and the entire country will develop cohesion when they encounter multicultural environment on the occasion of the sport event. SOC refers to the connectedness and relatedness between the societal units such as individuals, groups, associations and territorial units (Berger-Schmitt, 2000). It basically refers to interdependence among the members of the society, shared loyalty and solidarity. It is often reflected through the strength of social relations, shared values, communities of practice, common identity, sense of belongingness and trust among the members. Jenson (1998) has identified five extreme dimensions to SOC which include belonging-isolation, inclusion-exclusion, participation-non-participation, recognition-rejection and legitimacy-illegitimacy. Many authors have made attempts to relate SOC and QOL (Berger-Schmitt, 2000). The literature also provides evidence for adequate understanding of the role of cognitive and affective components in forming perceptions (Papadimitriou, et al., 2015). The sports events increase the 'feel good factor', though the effect might be short lived (Gibson, et al., 2014). The argument is that, the social cohesion must consider the attitude and behaviour of members. SOC is also based on social capital, which in turn is created by social relations. SOC involves aspects which are part of individual life situations and in this sense it becomes a part of QOL.

In regards to Environmental Aspects (ENV), there are several tourist-related issues which have bearing on environment of the country, which include transportation, tourist-related development, tourist activities, direct impacts of the lodging and cruise industries (Davies \& Cahill, 2000). There have been many efforts to minimize the impact of tourism on environmental degradation among which ecotourism trips play a dominant role. Ecotourism targets social, cultural and physical environment. Ecotourism facilitates tourism in an environmentally responsible manner. It promotes recreational programs that demonstrate a greater awareness and appreciation of nature, and a mode of travel that is sensitive to the host community (Yee, 1992). The World Travel and Tourism Council (WTTC) have initiated the Green Globe concept and it is committed to improvements in the environmental practice. The organization has programmes to educate the tourism agencies for promoting the eco-friendly tourism. Areas of high-value natural resources like oceans, lakes, waterfalls, mountains, unique flora and fauna, as well as great scenic beauty need to be protected by the country at any cost. It has to be noted that sponsoring of sport events and attracting a large number of visitors to the country can damage these environmental treasures of a country. There is a need to preserve the environment for the future generations. This calls for a detailed study related to the impact of sponsoring sports events on environment.

The above seven dimensions describe the socioeconomic aspects of a country in general. This study is focused towards understanding the impact of sponsoring sports events that can have relations with these dimensions of socioeconomic aspects. The literature review indicates that, there are no specific studies which have been undertaken to study this impact as such in the context of Qatar and this research attempts to quantitatively study the impact on these dimensions. 


\section{Methodology}

This research is based on a questionnaire survey with a sample size of 126 respondents. The respondents have been actively involved in organization of various sports events in Qatar. The events in which the respondents were involved include 2006 Asian Games, 2008 Asian Youth Wrestling Championships, 2009 FIVB Club World Championships, 2010 IAAF World Indoor Championships, 2011 Asian Football Cup, 2012 Asian Shooting Championships and the 2015 IHF Handball World Championships. The respondents were from the tourism industry and had experience as sports event managers, hotel managers, tourism advisors and leisure management professionals. The questionnaire development followed the usual procedure of screening the indicators of various dimensions of study and formulating the indicators of measurement. The questionnaire had two distinct components. The first collected data pertaining to the demographic details of respondents and the second part collected data for the quantitative analysis through a 5-point Likert's Scale (Appendix I). The inclusion criterion of respondents was the experience in sponsoring sports events and tourism industry. The respondents were spread across the tourism industry and included sports event managers, hotel managers, tourism advisors and leisure management professionals. A total of 300 questionnaires were distributed to the respondents. 132 were returned (return rate $44 \%$ ). However, after discarding the incomplete questionnaires, only 126 could be used for analysis.

The research was mainly restricted to descriptive statistics. The analysis was done using Microsoft Excel and SPSS. It included the calculation of mean, standard deviation, Skewness, Kurtosis and percentage distribution. The normality was tested using the Skewness and Kurtosis. The scores were averaged and classified into Bad, Poor, Average, Good and Very Good for the values ranging from 1 to 5 respectively. Thus, the percentage scores under each of these categories were determined. For each of the indicator of measurements, a classification of five categories was composed. The results were then plotted as histograms for graphical presentation. The radar diagram was developed based on the average score under each dimension for the overall representation of seven dimensions.

The perceptions of professionals involved in sponsoring the event and those in the tourism industry have been subjected to descriptive statistics to study the impact of sponsoring sports events on the seven dimensions of socioeconomic aspects of Qatar. The demographic distribution indicated that $68 \%$ of the respondents were male and $32 \%$ were female. $45 \%$ were in the age group of 25-35 years, $18 \%$ were in the age group of 36-45 years and 16\% were in the age group of 46-55 years. $6 \%$ were above 55 years old and the remaining in less than 25 years old. Considering the monthly income, $48 \%$ were in the range of $10 \mathrm{~K}-20 \mathrm{~K}$ Qatari Riyal (QAR), 18\% were in 20 -30K QAR, 22\% were in $5 \mathrm{k}-10 \mathrm{~K}$ QAR, $4 \%$ were above $30 \mathrm{~K}$ QAR and the remaining were in the category of below $5 \mathrm{~K}$ QAR. $56 \%$ had 6-10 years of experience, $22 \%$ had 2-5 years of experience and $12 \%$ had less than 2 years of experience. The remaining had more than 10 years of experience. Thus, there was a fair distribution of respondents in various demographic categories and the response was from the cross-section of the chosen category of managers. Following sections describe and summarize the results.

Table 1: Micro-Economic Aspects

\begin{tabular}{|c|c|c|c|c|c|c|c|c|}
\hline & \multirow[t]{3}{*}{ Mean } & \multirow{3}{*}{$\begin{array}{l}\text { Std. } \\
\text { Dev. }\end{array}$} & \multirow{3}{*}{$\begin{array}{l}\text { Jarque- } \\
\text { Bera }\end{array}$} & \begin{tabular}{l|} 
Bad \\
\end{tabular} & Poor & Avg. & Good & V. Good \\
\hline & & & & 1 & 2 & 3 & 4 & 5 \\
\hline & & & & (\%) & $(\%)$ & $(\%)$ & $(\%)$ & $(\%)$ \\
\hline $\begin{array}{l}\text { The firm based } \\
\text { capacities will } \\
\text { improve. }\end{array}$ & 3.7 & 1 & 6.260047 & 3.2 & 6.5 & 31.5 & 39.5 & 19.4 \\
\hline $\begin{array}{l}\text { The product } \\
\text { efficiencies will } \\
\text { improve. }\end{array}$ & 3.3 & 1.2 & 6.152509 & 8.1 & 19.4 & 24.2 & 26.6 & 21.8 \\
\hline $\begin{array}{l}\text { The process } \\
\text { efficiencies will } \\
\text { improve. }\end{array}$ & 3.3 & 1.3 & 5.764728 & 12.9 & 13.7 & 29 & 24.2 & 20.2 \\
\hline $\begin{array}{l}\text { New commercial } \\
\text { opportunities for } \\
\text { individual buyers will } \\
\text { be created. }\end{array}$ & 3.7 & 1.1 & 6.366986 & 2.4 & 12.1 & 24.2 & 35.5 & 25.8 \\
\hline $\begin{array}{l}\text { Information \& } \\
\text { communication } \\
\text { technologies will } \\
\text { improve. }\end{array}$ & 3.9 & 1.2 & 16.38994 & 5.6 & 9.7 & 15.3 & 32.3 & 37.1 \\
\hline Average & 3.58 & 1.1 & 8.18684 & 6.5 & 12.3 & 24.8 & 31.6 & 24.8 \\
\hline
\end{tabular}

Source: SPSS Output

\section{Micro-economic aspects}

Majority of respondents have perceived this dimension on the overall basis as good (31.6 percent) followed by very good ( 24.8 percent) and average ( 24.8 percent). Relatively lesser percentage of respondents have expressed that the impact of sponsoring an international event on micro-economic aspects as poor (12.3 percent) or bad (6.5 percent). With reference to the specific variables of study, the best perceived variable is "Information \& communication technologies (ICT) will improve" (Mean $=3.9 ; \mathrm{SD}=1.2)$. The weakest responses were observed as "The product efficiencies will improve" and "The process efficiencies will improve" (Mean $=3.3 ; \mathrm{SD}=1.2,1.3)$. The results thus indicate that, the impact of sponsoring the sports events would be the highest on the improvement of ICT infrastructure. However, the impact on improvement in product and process efficiencies would relatively be lower.

Table 2: Meso-Economic Aspects

\begin{tabular}{|l|r|r|c|c|c|c|c|c|}
\hline & Mean & $\begin{array}{c}\text { Std. } \\
\text { Dev. }\end{array}$ & Jarque-Bera & Bad & Poor & Avg. & Good & V. Good \\
\cline { 5 - 9 } & & & 1 & 2 & 3 & 4 & 5 \\
\cline { 5 - 9 } & & $(\%)$ & $(\%)$ & $(\%)$ & $(\%)$ & $(\%)$ \\
\hline $\begin{array}{l}\text { Innovation will be } \\
\text { promoted. }\end{array}$ & 3.7 & 1.2 & 8.297861301 & 5.6 & 11.3 & 25 & 25.8 & 32.3 \\
\hline $\begin{array}{l}\text { The performance of } \\
\text { the services and } \\
\text { products will } \\
\text { improve. }\end{array}$ & 4 & 1.1 & 15.90619031 & 3.2 & 8.1 & 18.5 & 29.8 & 40.3 \\
\hline $\begin{array}{l}\text { There is a need to } \\
\text { promote innovation. }\end{array}$ & 3.4 & 1.1 & 5.699726767 & 6.5 & 14.5 & 25.8 & 37.1 & 16.1 \\
\hline $\begin{array}{l}\text { Creative workforce is } \\
\text { the driver of business. }\end{array}$ & 3.2 & 1.3 & 7.405918097 & 14.5 & 16.1 & 21.8 & 29 & 18.5 \\
\hline $\begin{array}{l}\text { Firm performance } \\
\text { depends upon the } \\
\text { innovative abilities. }\end{array}$ & 3.5 & 1.1 & 5.070289 & 3.2 & 16.1 & 27.4 & 29.8 & 23.4 \\
\hline Average & 3.6 & 1.2 & 8.475997095 & 6.6 & 13.2 & 23.7 & 30.3 & 26.1 \\
\hline
\end{tabular}

Source: SPSS Output 


\section{Meso-Economic Aspects}

Majority of respondents have perceived this dimension on the overall basis as good (30.3 percent) followed by very good (26.1 percent) and average (23.7 percent). Relatively lesser percentage of respondents have expressed that the impact of sponsoring an international event on meso-economic aspects as poor (13.2 percent) and bad (6.6 percent). With reference to the specific variables of study, the best perceived variable is 'The performance of the services and products will improve' (Mean $=4.0 ; \mathrm{SD}=1.1$ ). The weakest response was observed on the item 'Creative workforce is the driver of business' (Mean $=3.2 ; \mathrm{SD}=1.3$ ).

Table 3: Macro-Economic Aspects

\begin{tabular}{|c|c|c|c|c|c|c|c|c|}
\hline & \multirow[t]{3}{*}{ Mean } & \multirow{3}{*}{$\begin{array}{l}\text { Std. } \\
\text { Dev. }\end{array}$} & \multirow{3}{*}{$\begin{array}{l}\text { Jarque- } \\
\text { Bera }\end{array}$} & Bad & Poor & Avg. & Good & V. Good \\
\hline & & & & 1 & 2 & 3 & 4 & 5 \\
\hline & & & & (\%) & (\%) & (\%) & (\%) & (\%) \\
\hline $\begin{array}{l}\text { The sponsoring of } \\
\text { sport event would } \\
\text { improve the total } \\
\text { amount of services } \\
\text { produced. }\end{array}$ & 3.5 & 1.3 & 9.790919 & 9.7 & 13.7 & 16.9 & 34.7 & 25 \\
\hline $\begin{array}{l}\text { The sponsoring of } \\
\text { sport event would } \\
\text { improve the total } \\
\text { amount of goods } \\
\text { produced. }\end{array}$ & 3.8 & 1.3 & 15.38487 & 9.7 & 8.9 & 15.3 & 28.2 & 37.9 \\
\hline $\begin{array}{l}\text { The sport event } \\
\text { sponsored would lead } \\
\text { to economic growth. }\end{array}$ & 3.6 & 1.2 & 9.325745 & 7.3 & 11.3 & 21.8 & 30.6 & 29 \\
\hline $\begin{array}{l}\text { The sponsoring of the } \\
\text { sport event would } \\
\text { reduce } \\
\text { unemployment. }\end{array}$ & 3.5 & 1.2 & 6.448421 & 7.3 & 9.7 & 29 & 29.8 & 24.2 \\
\hline $\begin{array}{l}\text { The sponsoring of } \\
\text { sports event would } \\
\text { provide price } \\
\text { stability. }\end{array}$ & 3.5 & 1.1 & 3.531093 & 5.6 & 10.5 & 34.7 & 31.5 & 17.7 \\
\hline Average & 3.6 & 1.2 & 8.8962096 & 7.9 & 10.8 & 23.5 & 31 & 26.8 \\
\hline
\end{tabular}

Source: SPSS Output

Macro-Economic Aspects

Majority of respondents have perceived this dimension on the overall basis as good (31 percent) followed by very good (26.8 percent) and average (23.5 percent). Relatively lesser percentage of respondents have expressed that the impact of sponsoring an international event on macro-economic aspects as poor (10.8 percent) and bad (7.9 percent). With reference to the specific variables of study, the best perceived variables is "The sponsoring of sport event would improve the total amount of goods produced" (Mean = 3.8; $\mathrm{SD}=1.3$ ). The weakest responses were observed on the items "The sponsoring of sports event would provide price stability", "The sponsoring of sports event would reduce unemployment" and "The sponsoring of sport event would improve the total amount of services produced" $($ Mean $=3.5 ; \mathrm{SD}=1.1,1.2,1.3)$.
Table 4: Employment

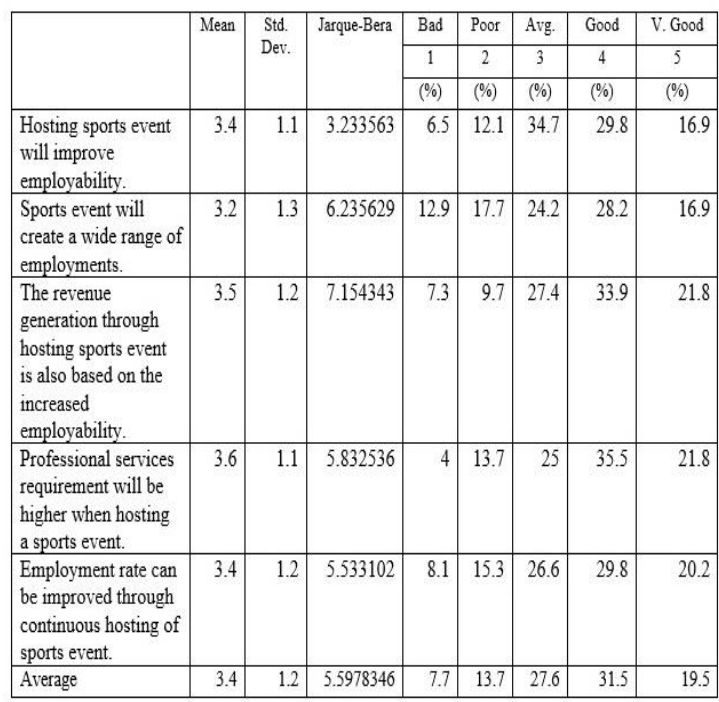

Source: SPSS Output

Employment

Majority of respondents have perceived this dimension on the overall basis as good (31.5 percent) followed by very good (19.5 percent) and average (27.6 percent). Relatively lesser percentage of respondents have expressed that the impact of sponsoring an international event on employment creation as poor (13.7 percent) and bad (7.7 percent). With reference to the specific variables of study, the best perceived variables is "Professional services requirement will be higher when hosting a sports event" (Mean $=3.6 ; \mathrm{SD}=1.1)$. The weakest response was observed on the item "Sports event will create a wide range of employments" $($ Mean $=3.2$; $\mathrm{SD}=1.3)$.

Table 5: Quality of Life

\begin{tabular}{|c|c|c|c|c|c|c|c|c|}
\hline & \multirow[t]{3}{*}{ Mean } & \multirow{3}{*}{$\begin{array}{l}\text { Std. } \\
\text { Dev. }\end{array}$} & \multirow[t]{3}{*}{ Jarque-Bera } & Bad & Poor & Avg. & Good & $\begin{array}{l}\text { V. Good } \\
\text {. }\end{array}$ \\
\hline & & & & 1 & 2 & 3 & 4 & 5 \\
\hline & & & & (\%) & (\%) & (\%) & (\%) & $(\%)$ \\
\hline $\begin{array}{l}\text { Hosting sports events } \\
\text { will improve QOL. }\end{array}$ & 3 & 1.2 & 4.715101 & 15.3 & 16.1 & 30.6 & 25 & 12.9 \\
\hline $\begin{array}{l}\text { Standard of living is } \\
\text { better in countries } \\
\text { which frequently } \\
\text { sponsor sports events. }\end{array}$ & 3.4 & 1.2 & 6.121524 & 8.1 & 13.7 & 25.8 & 32.3 & 20.2 \\
\hline $\begin{array}{l}\text { The sponsoring of } \\
\text { sports event will } \\
\text { provide a healthy } \\
\text { environment for } \\
\text { living. }\end{array}$ & 3.1 & 1.3 & 6.306514 & 16.9 & 16.1 & 27.4 & 21.8 & 17.7 \\
\hline $\begin{array}{l}\text { The sponsoring of } \\
\text { sports event will } \\
\text { improve community } \\
\text { connectedness. }\end{array}$ & 3.2 & 1.3 & 7.129684 & 14.5 & \begin{tabular}{ll|}
11.3 \\
\end{tabular} & 25.8 & 33.9 & 14.5 \\
\hline $\begin{array}{l}\text { The sponsoring of } \\
\text { sports event will } \\
\text { improve the } \\
\text { achievement of } \\
\text { individual goals of } \\
\text { citizens. }\end{array}$ & 3.6 & 1.2 & 6.589567 & 6.5 & 12.1 & 26.6 & 29 & 25.8 \\
\hline Average & 3.3 & 1.2 & 6.172478 & 12.3 & 13.9 & 27.3 & 28.4 & 18.2 \\
\hline
\end{tabular}

Source: SPSS Output 
Quality of life

Majority of respondents have perceived this dimension on the overall basis as good (28.4 percent) followed by very good (18.2 percent) and average (27.3 percent). Relatively lesser percentage of respondents have expressed that the impact of sponsoring an international event on quality of life as poor (13.9 percent) and bad (12.3 percent). With reference to the specific variables of study, the best perceived variables is "The sponsoring of sports event will improve the achievement of individual goals of citizens" (Mean $=3.6$; $\mathrm{SD}=1.2$ ). The weakest response was observed on the item "Hosting sports events will improve QOL" $($ Mean = $3.0 ; \mathrm{SD}=1.2$ ).

Table 6: Social Cohension

\begin{tabular}{|c|c|c|c|c|c|c|c|c|}
\hline & \multirow[t]{3}{*}{ Mean } & \multirow{3}{*}{$\begin{array}{l}\text { Std. } \\
\text { Dev. }\end{array}$} & \multirow{3}{*}{$\begin{array}{c}\text { Jarque- } \\
\text { Bera }\end{array}$} & $\mathrm{Bad}$ & Poor & Avg. & Good & V. Good \\
\hline & & & & 1 & 2 & 3 & 4 & 5 \\
\hline & & & & $(\%)$ & $(\%)$ & $(\%)$ & $(\%)$ & $(\%)$ \\
\hline $\begin{array}{l}\text { Sponsoring a sport } \\
\text { event would bind } \\
\text { the society together. }\end{array}$ & 3.5 & 1.2 & 6.340574 & 7.3 & 16.1 & 25 & 27.4 & 24.2 \\
\hline $\begin{array}{l}\text { Citizens will be } \\
\text { more sociable } \\
\text { through sponsoring } \\
\text { of sports event. }\end{array}$ & 3.6 & 1.1 & 9.544205 & 6.5 & 12.1 & 20.2 & 41.1 & 20.2 \\
\hline $\begin{array}{l}\text { Security systems } \\
\text { will improve } \\
\text { through hosting of } \\
\text { sports event. }\end{array}$ & 3.4 & 1.2 & 4.615484 & 8.9 & 11.3 & 32.3 & 29.8 & 17.7 \\
\hline $\begin{array}{l}\text { A sense of } \\
\text { belongingness to } \\
\text { the country will } \\
\text { improve through } \\
\text { sponsoring sports } \\
\text { event. }\end{array}$ & 3.2 & 1.2 & 5.024917 & 10.5 & 15.3 & 28.2 & 31.5 & 14.5 \\
\hline $\begin{array}{l}\text { Sports events unite } \\
\text { the citizens of } \\
\text { country. }\end{array}$ & 3.4 & 1.2 & 5.336864 & 7.3 & 16.1 & 25.8 & 33.1 & 17.7 \\
\hline Average & 3.4 & 1.2 & 6.1724088 & 8.1 & 14.2 & 26.3 & 32.6 & 18.9 \\
\hline
\end{tabular}

Source: SPSS Output

\section{Social Cohesion}

Majority of respondents have perceived this dimension on the overall basis as good (32.6 percent) followed by very good (18.9 percent) and average (26.3 percent). Relatively lesser percentage of respondents have expressed that the impact of sponsoring an international event on social cohesion as poor (14.2 percent) and bad (8.1 percent). With reference to the specific variables of study, the best perceived variable is "Citizens will be more sociable through sponsoring of sports event" (Mean $=3.6 ; \mathrm{SD}=1.1)$. The weakest response was observed on the item "A sense of belongingness to the country will improve through sponsoring sports event" $($ Mean $=3.2 ; \mathrm{SD}=1.2)$.
Table 7: Environmental Aspects

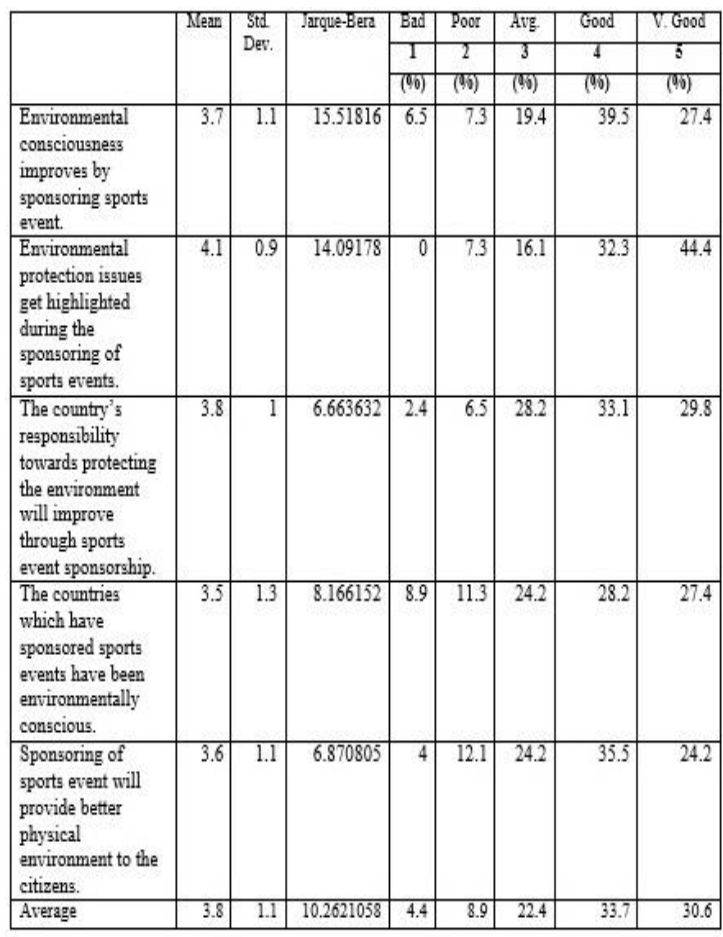

Source: SPSS Output

Environmental Aspects

Majority of respondents have perceived this dimension on the overall basis as good ( 33.7 percent) followed by very good (30.6 percent) and average (22.4 percent). Relatively lesser percentage of respondents have expressed that the impact of sponsoring an international event on environmental aspects as poor (8.9 percent) and bad (4.4 percent). With reference to the specific variables of study, the best perceived variable is "Environmental protection issues get highlighted during the sponsoring of sports events" (Mean $=4.1 ; \mathrm{SD}=0.9$ ). The weakest response was observed on the item "The countries which have sponsored sports events have been environmentally conscious" $($ Mean $=3.5 ; \mathrm{SD}=1.3$ ).

\section{The Overall Socioeconomic Impact}

The study reveals the fact that, the highest impact of sponsoring the sports event would be observed on the environmental aspects (Figure 1). The expectation is that, there would be awareness among the citizens about the importance of environmental protection (Mean $=3.8$ ). It was interesting to observe that, the second largest impact was on Micro, Meso and Macro-economic aspects of Qatari economy (Mean = 3.6). This was followed by Social Cohesion and Employment Aspects $($ Mean $=3.4)$. Finally, the least impact of sponsoring a sports event was on the improvement in Quality of Life (Mean $=3.3)$. These revelations can be very well justified because already environmental protection issues have been considered seriously and measures are in place to ensure sustainable growth of economy. So, sponsoring sports events can increase environmental awareness among the public. Also, there will be an immense opportunity to promote business, thus an opportunity of 
gaining international recognition. Also, it is justifiable that Social Cohesion of the country would improve and employment will also be strengthened due to the creation of many job opportunities owing to the magnitude of preparation and the products as well as the services which are required for hosting the event. As revealed through the study, among the seven dimensions of interest, the Quality of Life has the least significant impact as one sports event cannot produce any observable change in the QOL of the citizens of country.

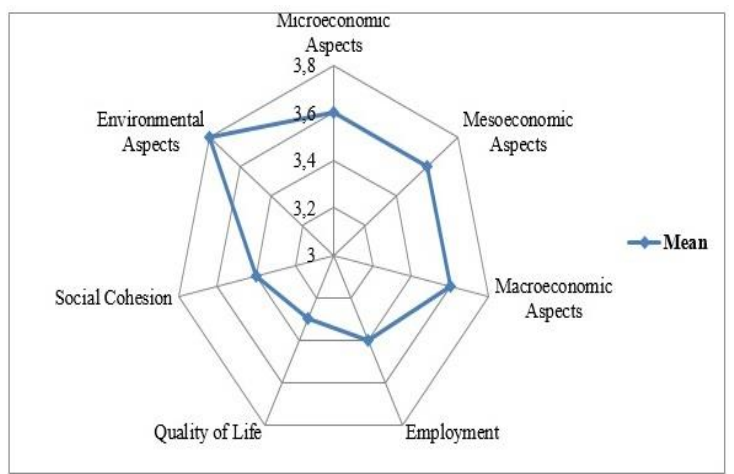

Figure 1. Overall Socioeconomic Impact

Source: Authors' own compilation

\section{Findings and Suggestions}

The findings of this research are based on the perceptions and expectations of managers in the tourism industry and do not represent the actual socioeconomic impact of hosting the sports events. As the respondents are in the sports industry since the past several years and have observed the trends and the socioeconomic impacts, they would be in a position to comment on the dimensions of study much better than the rest of members of society.

The findings indicate that, sponsoring sport events will support ICT growth which is a positive impact on the microeconomic aspects. The performance of the services and products is expected to improve, which is a positive impact on the meso-economic aspects. Sponsoring sports events would improve the total amount of goods produced, which is a positive impact on the macroeconomic aspects of the country. Thus, the country would benefit as a whole by sponsoring the sports events.

Professional services requirement is expected to be higher when hosting an international sports event, and thus, there is a positive impact on the employment opportunity. The improvement in professional services would expand business and there is a possibility to contribute to the country's GDP.

The sponsoring of sports event is expected to improve the achievement of individual goals of the citizens, thus producing a positive impact on the Quality of Life of citizens. This is quite an encouraging expectation and again the purpose of sponsoring the sports event is met with regard to the improvement in QOL too. The policy makers of the sports event may bid for higher numbers of such events to make use of its positive impact on the QOL.

Citizens are expected to be more sociable through sponsoring of the sports event as per the study and this is a positive impact on the Social Cohesion aspect. For any economy to grow, it is important for the citizens to develop social cohesion so that there would be a sense of solidarity and political stability in the country. So, again sponsoring the sports event is worth the effort.

Environmental protection issues get highlighted during the sponsoring of sports events and this has a positive impact on maintaining the flora and fauna of the country. A country like Qatar has always been particular about environmental protection and sustainable growth. So, sponsoring the sports event would contribute to this national objective.

\section{Conclusions}

The sponsoring of sports events on a large scale is definitely a major responsibility that has to be taken by the hosting country. This is because the whole country will be in the limelight during the happening of sports, particularly of the magnitude of FIFA World Cup. As Qatar is preparing itself for FIFA World Cup 2022, it has to consider seriously the impact of sponsoring the sports event on the socioeconomic aspects.

Having realised this fact, the paper has highlighted the outcome of a research with specific reference to seven dimensions of socioeconomic interest. The study results were based on sample size of 126 . It is imperative that no inferences or generalizations can be made based on this study, but there are certain key revelations which could be useful for the policy makers in the context of the impact of sponsoring sports events.

The research has indicated that, the highest positive impact of sponsoring sports events is expected to be on the environmental aspects. However, sponsoring of the sports events may not have a relatively high impact on improving the Quality of Life of the citizens, but it is expected to impact the Micro, Meso and Macroeconomic aspects of the country. As Qatar is geared towards sponsoring the FIFA event, this research is timely and could be of use to the policy makers. The research indicates that, the sponsoring would create a positive impact on the socioeconomic aspects of Qatar.

\section{References}

Andereck, K, Valentine, K.M, Vogt, C.M, and Knopf, R.C. (2007) A Cross-Cultural Analysis of Quality of Life Perceptions. Journal of Sustainable Tourism 15 (5), 483-502.

Andolfatto, D. (2005). Macroeconomic Theory and Policy, London: Simon Fraser University.

Berger-Schmitt, R. (2000). Social cohesion as an aspect of the Quality of the Societies: Concept and Measurement, TSER Project report of European Commission, Mannheim.

Brown, A,, \& Massey, J. (2001). Literature review: the impact of major sporting events. Manchester Institute for Popular Culture, Manchester Metropolitan University.

Carr, N. (2002). The Tourism Leisure Behavioural Continuum. Annals of Tourism Research, Vol., 29, No. 4, 972-986. 
Cefis E., (2001). Innovative Activities, Profitability and Heterogeneity, The 8th International J.A. Schumpeter Society Conference At Esrc Manchester, 2000.

Davies, T. \& Cahill, S. (2000). Environmental Implications of the Tourism Industry, Discussion Paper, Resources for the Future, Retrieved on 6th December, 2014 from: http://www.rff.org

Dopfer, K., Foster, J. and Potts, J. (2004). "Micro-MesoMacro." Journal of Evolutionary Economics, 263279.

FIFA, (2010), "2022 FIFA World Cup Bid Evaluation Report: Qatar". Retrieved on 10th October, 2014, from

http://www.fifa.com/mm/document/tournaments

FIFA, (2016). FIFA World Cup 2022 Stadiums. [Online] Available: http://www.qatar.to/stadiums/WorldCup-2022-stadiums.php [Accessed 25 July 2017].

Georghiou, L., Rigby, J., \& Cameron, H. (2002). Assessing the Socio-economic Impacts of the Framework Programme (ASIF), University of Manchester, London: PREST.

Gibson, H. J., Walker, M., Thapa, B. \& Coetzee, W., (2014). Psychic Income and Social Capital Among Host Nation Residents: A Pre-Post Analysis of the 2010 FIFA World Cup in South Africa. Tourism Management, Volume 44, 113122

Horne J. (2007). The four "knowns" of sports megaevents. Leisure Studies, London: Oxford Press.

Jenson, J. (1998). Mapping social cohesion: Canadian policy research network, Proceedings of policy research secretariat conference, Ottawa.

Kaplanidou, K., Karadakis, K., Gibson, H. Thapa, B., Walker, M., Geldenhuys, S. \& Coetzee, W. (2013). Quality of life, event impacts and mega event support among South African residents before and after the event: the case of the FIFA 2010 World Cup. Journal of Travel Research, 52(5), 631-645.

Karadakis, K., Kaplanidou, K. \& Karlis, G. (2010). Event leveraging of mega sport events: A SWOT analysis approach. International Journal of Festival and Event Management, 1(3), 170-185.

Klette T.J., Møen J., Griliches Z., (2000). Do Subsidies To Commercial R\&D Reduce Market Failures? Microeconometric Evaluation Studies, Research Policy 29, 1157-1163.

Ma, S. C. \& Kaplanidou, K. K., 2017. Legacy perceptions among host Tour de Taiwan residents: the mediating effect of quality of life. Leisure Studies, 36(3), 423-437.
Mamalakis, M. J. (1996). Poverty and Inequality in Latin America: Meso-economic Dimensions of Justice and Entitlements, Journal of Interamerican Studies and World Affairs 38, No. 2/3, 181-199.

Meethan, K. (2001) Tourism in global society. Places, culture, consumption. New York: Palgrave.

Papadimitriou, D. Kaplanidou, K. Apostolopoulou, A. (online 2015). Destination image components and word-of-mouth intentions in urban tourism: a multi-group approach. Journal of Hospitality Tourism and Research. doi: 1096348015584443

Smith, V.L. (2001). Tourism change and impacts. In. V.L Smith \& Brent, M. (eds.), Hosts and Guests Revis ited: Tourism Issues for the 21st century. New Yo rk: Cognizant Communication Corporation.

Stabler, M. J., P., A., \& Sinclair, M. T. (2010). The Economics of Tourism (2nd ed.). Abingdon: Routledge.

Stoneman P. (Ed)., (1995). Handbook of the Economics of Innovation and Technological Change", Blackwell Handbooks In Economics, Oxford UK and Cambridge USA.

Uysal, M., Perdue, R. \& Sirgy J. (Eds.), (2012). Handbook of Tourism and Quality-of-Life Research: Enhancing the Lives of Tourists and Residents of Host Communities. New York: Springer Publishers.

WTO (2010). Questionnaire on Tourism and Employment: Overview of Results, 2nd T.20 Ministers Meeting - Republic of Korea, Retrieved on December 5, 2014 from: http://t20.unwto.org/sites/all/files/docpdf/unwtoe mployment.pdf

Yee, J. G. (1992). Ecotourism Market Survey: A Survey of North American Ecotourism Operators. San Francisco: The Intelligence Centre, Pacific Asia Travel Association. 